\title{
Wikis: a collective approach to language production
}

\author{
ANDREAS LUND \\ InterMedia, University of Oslo, PO Box 1161 Blindern, N-0318 Oslo, Norway \\ (email: andreas.lund@intermedia.uio.no)
}

\begin{abstract}
Wikis represent a particular type of collaborative learning environment where collaboration can result in aggregated, collective products. This study makes the claim that such potential challenges language production practices in school where the individual learner's output is often the focus of attention. The argument is put forth by juxtaposing theory, literature review, and videotaped wiki activities. Wikis are examined in a sociocultural perspective, in particular the notions of collective zones of proximal development and sociogenesis - that we come to knowledge by taking part in activities where individuals relate to a greater collective that evolves over time and where language and material artifacts function as structural resources. A review of some recent research in CALL and Second Language Acquisition (SLA) seeks to form a backdrop for this study of collective language production. Empirically the argument is illustrated and supported by selected videotape transcripts of learner interactions involving the use of a wiki in an English as a Foreign Language (EFL) classroom. The study shows that learners work in and across activity types that create tensions between individual and collective, institutional and novel practices, but that the wiki also holds the potential for collective knowledge advancement and language development.
\end{abstract}

Keywords: wiki, collective language production, sociocultural theory

\section{Introduction}

A wiki can be characterized as a "freely expandable collection of interlinked web pages, a hypertext system for storing and modifying information - a database, where each page is easily edited by any user with a forms-capable Web browser client" (Leuf \& Cunningham, 2001:14). For language learning it holds a potential for collectively producing, organizing and sustaining textual (and, increasingly, visual and auditory) resources. Wikis represent a rapidly expanding phenomenon but there is a need for studies that address their use in education and how they can be utilized in school subjects (Lund \& Smørdal, 2006). 
Due to the wiki's collective orientation, user-produced networked structure, and meta features that track and guide the activities, we see an environment that to a great extent relies on learner interdependence. The questions I ask and discuss in this exploratory study are: what kind of interdependent activities do learners engage in and what is the impact of wikis on collaborative work in the foreign language learning classroom? Activity is here used as in activity theory (Engeström, 1987; Kaptelinin \& Nardi, 2006), the basic unit of analysis for examining purposeful, mediated, and social action. Activity embodies the dialectical relationship between cognition and context, agency and cultural tools, subjects and the object(s) they construct. The central claim in the article is that wiki activities challenge established language production practices in school, and involve an epistemological shift for those involved. This claim is theoretically linked to the sociocultural notion of sociogenesis - that we come to knowledge by taking part in collective activities that evolve over time, and where language and material artifacts function as collective structural resources (Valsiner \& van der Veer, 2000). A review of current trends in CALL and SLA seeks to relate sociogenesis to language production in a wiki and, thus, to better assess the justification of the claims. In order to contextualize the theoretical argument I report from an empirical study of wiki use in an EFL classroom in Norway (Senior High School foundation course, age 17). It is important to note that this material is not included as empirical "evidence" for claims but as part of the reasoned judgment or assertational logic that constitutes analytical generalization; i.e. "the extent to which findings from one study can be used as a guide to what might occur in another situation" (Kvale, 1996:233). Also, it is important to note that the focus of the current study is restricted to the conditions under which collective language production emerges. It does not aspire to make claims as to the possible effects of a wiki on the quality of the language production. The rationale is that language learning cannot be seen as de-contextualized from the socio-technical affordances and constraints of the wiki learning environment and that we also need studies that address such issues in order to evaluate language learning processes and outcomes.

Collaborative practices are increasingly seen as keys to going beyond what we know and developing the capacity to solve complex problems that are typical of the knowledge society but beyond the capacity of the individual. Collaboration involves participants jointly working together on a task and not by dividing it into individual subtasks that are later assembled (Dillenbourg, 1999). Consequently, collectives of various types and sizes attract much interest (Engeström, 1987; Hakkarainen, Palonen, Paavola, \& Lehtinen, 2004; Lindkvist, 2005; Lund \& Smørdal, 2006; Säljö, 2000). In the following, the notion of collective production is related to product as well as process. As product it represents the aggregated output of a collaborative effort and one that cannot be reduced to the separate input of individuals (Stahl, 2006). As process, collective production involves (often transitory) networks of agents and cultural tools oriented towards developing insights, and towards the object of the activities (Lindkvist, 2005; Lund \& Smørdal, 2006).

Mediating technologies and cultures-of-use reciprocally influence each other (Thorne, 2003), and communicative activity articulates as well as changes cultures (for the relationship between cognition and the communicative tools we use, see e.g. Heim, 1987; Ong, 1982/1988). Thus, there is a need for more theoretical development as well as empirical studies that can inform pedagogical practice; how learning and knowledge 
advancement can be conceived as processes of sociogenesis (Ludvigsen, in press; Lund, 2005; Valsiner \& van der Veer, 2000).

The phenomenon and the research questions are approached by first briefly reviewing recent literature on some current trends in CALL and SLA research and by placing this contribution in relation to it. Next, an exploration of the concept of sociogenesis is followed by a characterization of the wiki. Then the context and research methods used within a longitudinal, interventionist study are briefly presented before seeking to make the argument empirically visible through selected sequences of interaction data from an EFL project involving the use of a wiki. Finally, some implications of wiki practices are discussed.

\section{Relevant research}

Based on the introductory claim that wikis hold transformational potential, it seems necessary to view such technologies in light of recent appraisals of the CALL field as well as recent trends in SLA. Thus, the current section should not be read as a comprehensive literature survey but rather as a selected review in order to theoretically frame the use of wikis. To my knowledge there are very few studies that address wikis in a CALL perspective, and the purpose of this section is thus to generate a background against which the affordances of wikis can be better understood.

\subsection{Critical research on CALL}

Looking at a number of surveys on CALL research, one is struck by the self-critical approach. In an edited volume on CALL research (Egbert \& Petrie, 2005) several authors assess the field as a whole. Egbert (2005:3) identifies a "fallacious inclination to test technologies rather than theories" and asks for a research focus that takes context as a key to understanding all the variables that go into CALL practices. Tasks, tools, agents, activities and the affordances of the many contexts (online, offline, school, outof-school) all need to be addressed from a unifying perspective if we are to make sense of practices and support productive development (see also Lund, 2006 for discussions of contextual factors). This observation seems to be representative of several recent assessments of the status of CALL.

For example, Huh and $\mathrm{Hu}$ (2005) identify three main weaknesses in CALL research. First, they find that CALL research needs to be better connected to theories of SLA. Second, the authors point to indications of skewed selection of data and comparative neglect of data that does not support claims. Third, they warn against technocentricity and, especially, when only quantitative methods have been used to gauge the "effect" or "effectiveness" of a particular technology.

Bax (2003) criticizes inconsistent use of terms and unclear criteria as to what constitutes a category of CALL. For instance, what is it that justifies categories labeled Structural or Communicative CALL? Is it features in the particular technology, dominant use of the technology, representations of historical progression, or how technologies are sought aligned with aims and policies in curricula? Also, we know from substantial research that the same type of software might be embedded in very different practices across classrooms, institutions, and learning cultures (e.g. Lund, 2004; Thorne, 2003; 
Warschauer, 1999; Zhao, Pugh, Sheldon, \& Byers, 2002). This calls for a focus on the activities that ICTs mediate.

Such perspectives can be found in studies that address the intersection of CALL and pedagogical practice as well as communicative practices developing in out-of-school contexts (e.g. Kern, 2006; Kern, Ware \& Warschauer, 2004; Lund, 2006; Thorne \& Payne, 2005). For example, after first reviewing research on synchronous computer mediated communication (SCMC) Thorne and Payne (2005) find that our notion of literacy is changing, and with it our concept of what it means to be competent in a situation where everyday communicative activities are undergoing change. The authors point to the circumstance that such transformation is largely an out-of-school process as these contexts seem to adopt new cultural tools more readily than educational settings (see also Pew Internet and American Life Project, 2002 for identical conclusions on the wider use of technologies).

Similarly, Kern (2006:191) finds that "computer cultures are subject to transformation not just by hardware and software design but also by computer users". He points out the need for more qualitative and longitudinal studies that have more explanatory power than studies that are of short duration and rely on quantitative analysis. Change can be found in practices that evolve over time, that move across contexts, and that involve new types of discourse and genres. The challenge for education is to prepare learners for participating in and ultimately improving such practices.

This brief survey of recent issues in CALL research indicates an increased attention to contextual, social, and cultural aspects of language learning. Thus, the field can be said to experience a process of reconstruction. Although this may be incremental, the trend towards a social (as an extension of e.g. technological or cognitive) perspective on CALL is clearly visible. But there are few, if any, studies that explicitly address sociogenesis and the relationship between individual and collective approaches, although this aspect is present in some (e.g. Hampel, 2006; Lund, 2006; Warschauer \& Kern, 2000). However, looking at the broader field of SLA, and in particular recent contributions from sociocultural perspectives, this aspect of language learning becomes more visible.

\subsection{The social turn in SLA}

The literature reflecting sociocultural approaches to (foreign) language learning is extensive; sometimes comparing, frequently critiquing, and often radical in its departure from cognitive perspectives that largely dominated the latter half of the 20th century. What follows is a concentrate of some recent and influential work in the field (Johnson, 2006; Lantolf, 2000b; Lantolf \& Thorne, 2006; Vollmer, 2002; Watson-Gegeo, 2004; Zuengler \& Miller, 2006).

First, there are epistemological as well as ontological implications. Adopting a sociocultural perspective implies a shift from theories of universal generative grammars, genetic blueprints and innate structures. Instead, there emerges a view of language as cultural conventions and sets of resources, and as a cultural tool that serves to invoke and share attention (Tomasello, 2003; Watson-Gegeo, 2004). Language use has primacy over language structure in the sense that formal aspects cannot be separated from meaning, emotion, and activity. 
A second commonality is found in the shift from individual acquisition to artifactmediated collaborative participation. This particular shift seems to be influenced by activity theory (Engeström, 1987; Engeström, Miettinen, \& Punamäki, 1999), which takes the total activity system (agent, object, tool, community and its rules and division of labor) as its unit of analysis. In a language learning context this means there is a change in perspective from individual language acquisition to social language acquisition through participating in speech communities (Brutt-Griffler, 2004; Roberts, 2001; Watson-Gegeo, 2004). Strictly speaking, language as communication (and not as structure and discrete elements) does not make sense on a purely individual or decontextualized level. A speech community unit of analysis appears to be useful when we approach emergent language practices across cultures and contexts - offline and online - since such practices develop collectively in groups and (sub-)cultures, as macroacquisition (Brutt-Griffler, 2004). This does not mean that the individual disappears but that it is always related to the context and community in which s/he acts.

Third, and as a consequence of the previous items, dialogism (Linell, 1998) emerges as a particularly powerful concept. When Bakhtin (1986/2004:143) writes that "I live in a world of others' words and my entire life is an orientation in this world", it is a statement that identifies dialogue as constituting a third space between oneself and the other; as "a way of communal existence" (Kostogriz, 2005:193). But this communal existence is not one of harmony or equality. There are contesting and conflicting worldviews, interlocutors are unequal and positioned differently (class, race, gender).

Finally, there are implications for classroom practices. In a sociocultural view of SLA the learner is not just an individual who on encountering a foreign language processes and assimilates vocabulary and syntax. Rather, learners are seen to participate in different speech communities where they draw on social resources (other participants, institutional affordances), material resources (PCs, networks, applications), and semiotic resources (signs, genres). This involves tasks and assignments that capture communicative situations involving agents and mediating means (for more detailed discussions see e.g. Gibbons, 2006 for bridging theory, practice and discourses; Hall \& Verplaetse, 2000; Hall, Vitanova \& Marchenkova, 2005 for dialogic approaches; and Hawkins, 2004; Lund, 2004; 2006 for teacher education issues).

\subsection{A sociocultural perspective: sociogenesis}

One fundamental assumption in a sociocultural perspective on learning is that cognition cannot be separated from its broader cultural contexts, social, institutional, and historical. It is a perspective that seeks to overcome the Cartesian dichotomy of mind and body, cognition and context. Language is not understood as a reflection of mental processes but is seen to mediate and shape thinking (along with other cultural tools, semiotic and material; for extensive discussions see also Lantolf, 2000a; Vygotsky, 1978, 1986; Wells, 1999; Wertsch, 1998).

While sociocultural theory in many ways has become synonymous with the theoretical work of Vygotsky, Valsiner and van der Veer (2000) show that similar perspectives can be traced throughout the 19th century in Europe as well as in American pragmatism. Studying the social mind and in particular intellectual 
interdependency, how the idea is socially constructed, the authors discuss the concept of sociogenesis - "the social genesis (i.e. development, emergence) of the person" (op. cit.:3). With its emphasis on emergence of psychological phenomena and their social origin, sociogenesis is at the heart of a sociocultural perspective.

The concept of sociogenesis also transcends the more individual aspects of learning and signals an epistemological shift from learning as a process within minds to learning as process between minds and "how we use language to think together", to quote Mercer's (2000) apt book title. Perhaps this can best be observed by comparing Vygotsky's original notion of the zone of proximal development (ZPD) with more recent interpretations. In Vygotsky's (1978:86) much quoted definition of the ZPD he states that

It is the distance between the actual developmental level as determined by independent problem solving and the level of potential development as determined through problem solving under adult guidance or in collaboration with more intelligent peers.

From Vygotsky's internalization perspective, more recent interpretations have addressed the collective and cultural aspects of the ZPD (Engeström, 1987; Daniels, 2001; Kaptelinin \& Nardi, 2006). These researchers point to how a one-dimensional, "vertical" interpretation can reduce the ZPD to a mechanistic construct of support. Daniels (2001:67) observes:

Multiple and possibly conflicting discourses with different sociocultural historical origins may be in play within the ZPD. This view of the ZPD as the nexus of social, cultural influences takes us far beyond the image of the lone learner with the directive and determining tutor. It provides a much expanded view of the 'social' and the possibility of dialectical conception of interaction within the ZPD.

This is an expansive, collective and dynamic view of the ZPD and it results in a need to constantly redefine it according to learners' needs and opportunities. It also means that the ZPD can be viewed as inhabited by individuals as well as a collective who can create a common ZPD through their interactions (Daniels, 2001). The relationship between sociogenesis and a collective view of the ZPD seems to hold an analytical potential when approaching learning in wikis, which are by their very nature arenas of collective activity. A wiki has the potential to advance and realize a collective ZPD but its features and affordances must be socially enacted. There is no simple causality between technological features and use.

A main point in this section is that, taken together, trends in CALL research, the social turn in SLA, influence from sociocultural perspectives, and the rapid growth of collectively oriented, networked technologies converge in a need for studies that pay attention to collective language learning. However, in the following the focus is on collective activities underlying language production and the content such activities result in, and not so much the linguistic outcome. We first need to map the wiki's sociotechnical affordances and interactions around, in, and through the wiki in order to understand the linguistic conventions and language learning potential that emerge. 


\section{What is a wiki?}

The first wiki (from Hawai' 'ian wiki-wiki = quick, fast) was created in 1995 by Howard Cunningham as a novel way of developing private and public knowledge bases (Leuf \& Cunningham, 2001), a net-based, hypertextual and collective authoring tool. By pressing an editing button, every page can be changed (or deleted), and the new version is immediately available online. The most famous offspring is the online encyclopedia Wikipedia <www.wikipedia.org> which, with its close to 30,000 contributors and 4,600,000 articles in (currently) 229 languages (Riehle, 2006), embodies the idea of a potentially collective, democratic, open, and dynamic design. However, this somewhat romantic vision has been challenged by vandalism and "information wars" and required registration is not uncommon in wikis.

Thus, a wiki holds technology as well as community aspects. What separates the wiki from other online, distributed environments such as e.g. Learning Management Systems (LMS) and groupware applications is its open architecture. The design implies that structure is not imposed or pre-determined (as in an LMS) but emerges as a result of participation. When wiki activities enter schools there are consequences for learning and teaching. Content and networked structures are built from within as users add material and make use of a simplified hypertext mark-up language to create links and add features. In LMSs and groupware, activities are often linked to individual work (learners' personal folders etc) that can be shared later, while in a wiki it is the collective (e.g. class) activities that give rise to content formation, structure, and (indefinite) growth. And while degrees of interdependence can be observed when people jointly draw and take notes (cf. the use of mind map in section 5), the wiki affords immediate and unlimited participation due to its distributed character; interdependency is not an option but its rationale.

The underlying application for Wikipedia, MediaWiki, is identical to the one used in the project reported on in this paper. The MediaWiki affords collective language production through two types of link. In editing mode, by simply enveloping a word or cluster of words in square brackets (e.g. [[Bush]] in Figure 1), the enveloped unit will appear as a red link in document mode (note that red links appear as underlined text, blue links appear as bold text in the figure). Clicking on the red link will call up an empty page with a name identical to that in the brackets, a NameSpace. This new space can then be developed by one or many contributors. As soon as there is content in the NameSpace the color of the link will turn from red to blue (e.g. Michael Moore in Figure 1). In this way links function as indicators of existing content or invitations to create new content, giving rise to opportunities for dynamic and perpetual growth.

In addition, a wiki will typically afford a series of meta-features such as the history of a page (including comparison of versions and rollback to earlier versions), notification of revisions, and discussion spaces assigned to particular pages. In this way, producing content and structure in the wiki can be accompanied by comments, discussion, and annotations. This is where the interdependent and collective orientation of the wiki emerges.

As technological features do not automatically result in specific or intended use, it would seem that there is a great need for studies that examine the activities that constitute working with, through and in a wiki. Also, we need a perspective on language learning that addresses the relationship between humans and the cultural tools they use for communication. This relationship will be addressed in the following section. It is 


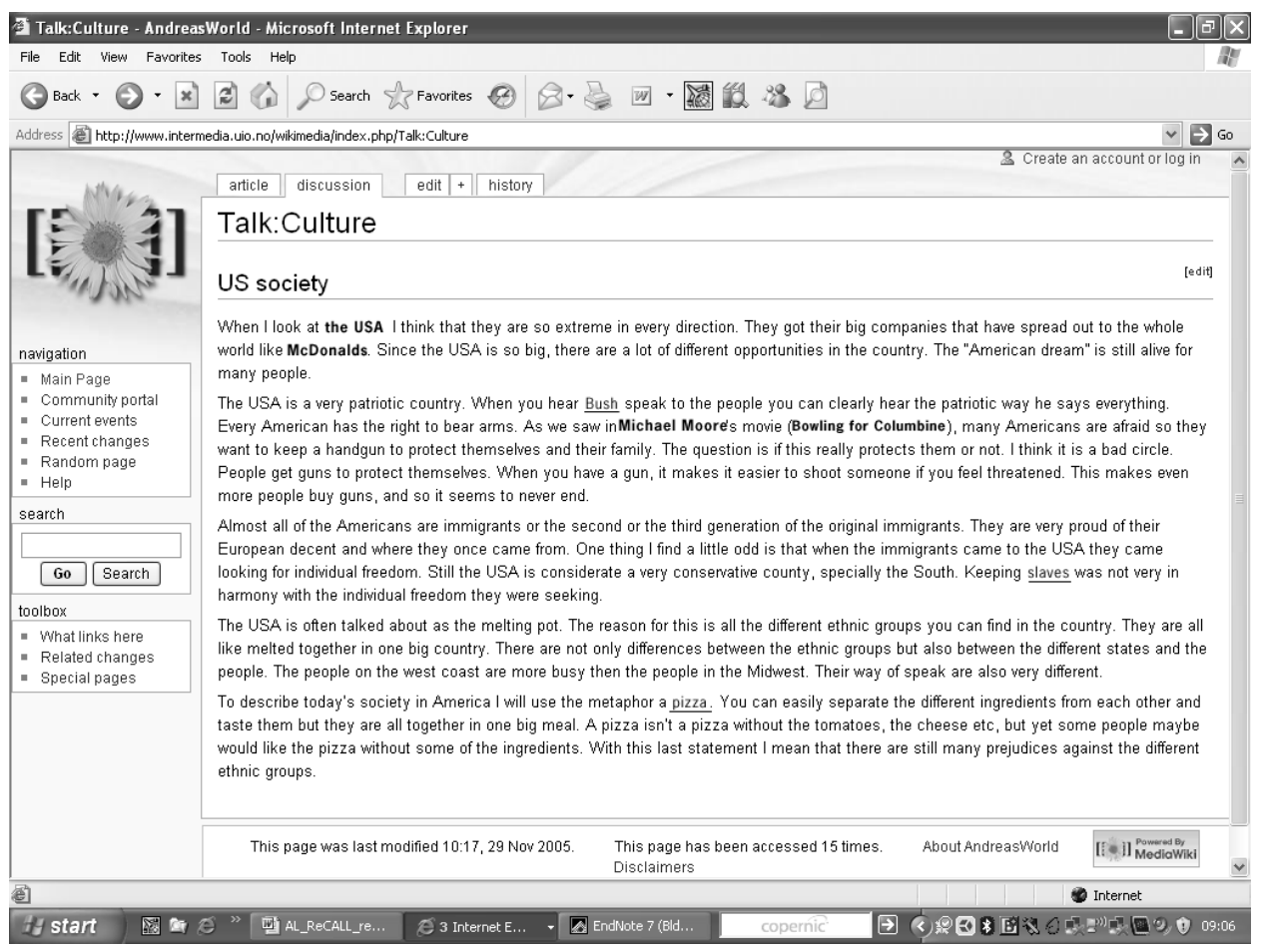

Fig. 1. Screenshot from wiki production (note that red links appear as underlined text and blue links appear as bold text)

important to emphasize that the introduction of the wiki in this setting is a deliberate intervention to observe possible tensions between traditional individual writing and the novel situation which involves collective knowledge advancement in the form of collective language production. Consequently, the wiki is as much a particular setting or environment for a collective ZPD as a tool that mediates such processes.

\section{5 “...it is a win/win situation" - a case study}

\subsection{Context and activity}

At Hillside Senior High School EFL learners worked with the MediaWiki application in the fall and spring semester 2005-2006. This is part of an ongoing longitudinal interventionist (or design-based) study (Brown, 1992; Design-Based Research Collective, 2003) on collective cognition (Lund, 2005). Thus, the wiki is an intervention intended to support as well as articulate collective knowledge advancement. Previous use of the LMS showed that production either remained individual or, when learners worked together in pairs or small groups they saved their work in assigned folders so that a larger and more collective output was not realized. Local production with ownership took priority over networked, collective production.

In the following the focus is on one class (31 learners, age approximately 17) participating in the mandatory foundation course in EFL. Each learner has access to a 
laptop hooked up to the internet via a wireless broadband connection. Thus, we have a situation in which learners can work together face-to-face as well as in distributed mode through the wiki. This setting serves two purposes. It affords spoken as well as written interactions and it makes it possible to examine the potentially different strategies that learners employ as they work in both modes, offline and online. The entire empirical data corpus includes:

- $\quad$ one audio taped lesson when the learners were first introduced to the MediaWiki;

- $\quad$ eight videotaped lessons in which the class worked on a project spanning two weeks in November - December 2005;

- $\quad$ the growing MediaWiki content comprising pages, links, and comments;

- written response to a questionnaire from 27 learners.

From this material two videotaped sequences and learner responses to a questionnaire are examined in order to contextualize and visualize the two dominant activity types (see Lund \& Smørdal, 2006 for extended analysis). The activity of a small group of language learners is taken as the unit of analysis.

The current section presents a qualitative and exploratory account of the lived situation, "a concrete realization of a possibility that exists at the collective level" (Ercikan \& Roth, 2006:15). To bridge the gap between the lived situation (emergent classroom practice) and what can be said about it (analytical account) is, of course, an interpretation but an interpretation that is grounded in the previous sections on theoretical approach and review. It is at the intersection of conceptual argument, review and empirical sampling that the claims and analytical generalization (Kvale, 1996) are supported. Thus, the particular case is not sought to be generalized in a strict sense. Rather, it indicates what is possible given certain technological and social contexts. Tables 1 and 2 reflect interaction analysis (IA) of situated, distributed, and multilevel communication in real time as developed by e.g. Jordan and Henderson (1995) and Roth (2005). From an ethnographic approach (although some researchers also use ethnomethodology) IA uses video recordings and video logs to focus on how participants explore and exploit social and material resources, what they say and do, and to what extent a phenomenon is robust across situations and in trajectories. Roth (2005) has expanded on this approach by addressing multiple levels of communicative actions (gestures, prosody), and by "zooming" in and out of levels, Roth documents the many semiotic resources that mediate communication.

The videotaped corpus from which the two excerpts are taken has also been transcribed and analyzed so as to visualize how individual actions and turns constitute activity types. Tables 1 and 2 indicate how this has been achieved. However, in this paper the focus is on the activity types, how events are structured and bounded, and not so much on the interactional level. Activities around and through as well as in the wiki constitute the analytical focus. Also, the learners used a series of artifacts such as (analog) mind map, word processor, learning management system (LMS), and search engines. The intention has been to capture the totality of the cultural tools and how they were integrated in the overall activity.

Immediately after the wiki experience learners were asked to complete a response form with open-ended statements. The response data is here analyzed as polyphonic and 
heteroglossic voices (Bakhtin, 1979/2000), not as belonging to certain categories. Also, the response form was used to glean reasons for opinion and not just opinion. Thus, the questionnaire is seen as a particular cultural tool mediating participants' situated reflections (Lund, 2004), and adds a metadata layer to the study. The combination of activity data and response data serves to gain increased insight in how the wiki experience materialized as well as how it was perceived by the participants, their "lived" experience.

\section{2 “Our” USA}

For the fall term 2005, the class in question had focused on the USA, as it is one of the primary topics in the national curriculum. The assignment (developed by the teacher and learners together) was to use the MediaWiki to construct the young learners' collective and multiple perception of the US, hence the title "Our" USA. This work was carried out over two weeks, altogether eight lessons. Some learners also added material outside of school hours. The teacher emphasized that the learners should exploit the wiki's editing facilities for content as well as language improvement. Otherwise, this was a completely open task with no directions as to the development of content and form.

From the beginning there was intense production of topics and corresponding texts. For example, one dyad developed a space on "soaps" that managed to bind together typical elements (e.g. cliffhangers, the evil family member) with the expectations of the audience and examples of such series. In the following we observe this dyad, Catherine and Marie (anonymized). From the videotaped material I have selected two episodes, A and B, (see Tables 1 and 2). The reason for this selection is that they represent two typical activity types that emerged during the project: first local content development and then the collectively generated network. These two activity types are not dichotomous but represent degrees of collectivity in the process. Also, they serve to show how collaborative processes of talk and writing materialize in the wiki content and structure. By keeping a focus on the same learners in two different activity types we can compare and contrast activities as they evolve.

Tables 1 and 2 present transcribed videotaped interactions. Turns are numbered, and overlapping utterances are denoted by square brackets. Learners speak in English, but occasionally a Norwegian word or phrase enters into the exchange (in italics).

Episode A takes place early on in the project (second lesson). Catherine and Marie have decided to give their views on what they take to be a typical manifestation of American culture, the type of TV series known as "soaps". They use a hand-drawn mind map in order to get an overview of typical "soap" features, they write article drafts using a word processor, and occasionally they place material in their folder in the LMS. Thus, episode A shows local, collaborative content building.

The episode starts with a contract of mutual support (turns 1-4). Next the learners orientate themselves towards the task and divide the labor between them $(5-14)$. There is some asymmetry as Catherine explores the term soaps $(6,9)$ and what acting in such a series involves $(11)$, while Marie mostly takes notes $(6,11,14)$. Near the end of the episode Marie elaborates on this topic (12). The episode is characterized by the use of the shared mind map (1-4) and joint activity that materializes in verbal as well as gestural moves, i.e. a common ZPD. The mind map serves to mediate the development 
Table 129 November 2005.01:20 min. Activity: defining "Soaps"

Material resources: mind map, word processor, learning management system

\begin{tabular}{|c|c|c|}
\hline Actor & Speech & Gestures/use of resources \\
\hline 1 Catherine & $\begin{array}{l}\text { Since I'm helping you, then you } \\
\text { will have to help me afterwards }\end{array}$ & $\begin{array}{l}\text { Catherine turns to Marie who } \\
\text { is working on the mind map } \\
\text { showing typical features of } \\
\text { soap series }\end{array}$ \\
\hline 2 Marie & Yep & Working on the mind map \\
\hline $3 \mathrm{C}$ & Deal? & Studying the mind map \\
\hline $4 \mathrm{M}$ & [It's a deal & Working on the mind map \\
\hline $5 \mathrm{C}$ & $\begin{array}{l}\text { And it's... eh, soaps are very long } \\
\text { lasting.. go on for several years }\end{array}$ & \\
\hline $6 \mathrm{M}$ & [many years & $\begin{array}{l}\text { Writing down comments } \\
\text { from Catherine }\end{array}$ \\
\hline $7 \mathrm{C}$ & [and then there & \\
\hline $8 \mathrm{M}$ & (mumbles to herself) .... and... & Turns towards Marie \\
\hline $9 \mathrm{C}$ & $\begin{array}{l}\text { And... the actresses or actors they're, they } \\
\text { work with the soaps their whole life, and } \\
\text { very seldom they go over to the movies } \\
\text { Don't you think that is the way it is? }\end{array}$ & \\
\hline $10 \mathrm{M}$ & Yes... (inaudible) four thousand... & Marie takes notes \\
\hline $11 \mathrm{C}$ & $\begin{array}{l}\text { And if the, if the actors have to .. } \\
. . \text { mmm maybe leave the series, then the, } \\
\text { the person in the series die, or something, or } \\
\text { go on a trip or goes in a coma or something } \\
\text { or just disappears, maybe go to jail or... }\end{array}$ & from Catherine's comments \\
\hline $12 \mathrm{M}$ & $\begin{array}{l}\text { Yeah, or sometimes they just switch the } \\
\text { actor, they put a new one in there... }\end{array}$ & Turns towards Catherine \\
\hline $13 \mathrm{C}$ & [yeah & \\
\hline $14 \mathrm{M}$ & & Takes notes \\
\hline
\end{tabular}

of ideas into topics and their attributes (soaps and characteristic genre features). It emerges as a vital tool in their meaning making and content formation activities. In this initial phase of the assignment, the learners use local resources and do not use the wiki to create links that serve as invitations to develop their contributions. This is typical of the class as a whole. Learners worked in "self-contained" units (dyads, groups) where local ownership of the written products had priority over the networked and distributed result. 
Table 2 2. December, 01:17 min. Activity: production of hypertext in MediaWiki Material resources: mind map, World Wide Web, Wiki

\begin{tabular}{|c|c|c|}
\hline Actor & Speech & Gestures/use of resources \\
\hline 1 Marie & You can make some of the, eh.... links red & \\
\hline 2 Catherine & [blue & \\
\hline $3 \mathrm{M}$ & Red! & $\begin{array}{l}\text { Turns towards Catherine's } \\
\text { screen, pointing to text }\end{array}$ \\
\hline $4 \mathrm{C}$ & New York City! & \\
\hline $5 \mathrm{M}$ & Clever & $\begin{array}{l}\text { Pointing to specific place in } \\
\text { text }\end{array}$ \\
\hline $6 \mathrm{C}$ & Forrest Gump! & $\begin{array}{l}\text { Both focusing Catherine's } \\
\text { screen, Catherine is writing }\end{array}$ \\
\hline $7 \mathrm{M}$ & [clever! & \\
\hline $8 \mathrm{C}$ & $\mathrm{OK}$ & \\
\hline $9 \mathrm{M}$ & Elvis & \\
\hline $10 \mathrm{C}$ & And do you do... like this... or the & $\begin{array}{l}\text { Pointing out a combination } \\
\text { of keystrokes }\end{array}$ \\
\hline $11 \mathrm{M}$ & & $\begin{array}{l}\text { Pointing out a combination } \\
\text { of keystrokes }\end{array}$ \\
\hline $12 \mathrm{C}$ & $\begin{array}{l}\text { double spacing, ja ikke double spacing } \\
d a, \text { men... yeah, I understand, yes }\end{array}$ & Pause. Catherine is writing \\
\hline $13 \mathrm{M}$ & Forrest Gump & \\
\hline $14 \mathrm{C}$ & Mhm.... Very clever! & $\begin{array}{l}\text { Said with irony and, } \\
\text { "Norwegian" intonation }\end{array}$ \\
\hline $15 \mathrm{M}$ & Yep, I am very clever! & $\begin{array}{l}\text { Repeats intonation. Marie } \\
\text { turns toward her own screen } \\
\text { and resumes work }\end{array}$ \\
\hline $16 \mathrm{C}$ & Ehm..... & \\
\hline $17 \mathrm{M}$ & Why..... is this coming in a special box? & $\begin{array}{l}\text { Makes (blue) link to } \\
\text { external resource. }\end{array}$ \\
\hline $18 \mathrm{C}$ & $\begin{array}{l}\text { Viet Nam war... } \\
\text { Elvis? }\end{array}$ & $\begin{array}{l}\text { Speaking to herself. Pause. } \\
\text { Both speaking to themselves, } \\
\text { both making red links from } \\
\text { the Forrest Gump text, both } \\
\text { concentrating on Catherine's } \\
\text { screen }\end{array}$ \\
\hline $19 \mathrm{M}$ & And segregation .... Og Elvis må du ta med & $\begin{array}{l}\text { Marie concentrates on her own } \\
\text { screen. Both writing separately. }\end{array}$ \\
\hline $20 \mathrm{C}$ & mmmmmm... & $\begin{array}{l}\text { Marie turns toward } \\
\text { Catherine's screen }\end{array}$ \\
\hline $21 \mathrm{M}$ & John F. Kenney.... color red & $\begin{array}{l}\text { Catherine is writing, Marie } \\
\text { turns to her own screen }\end{array}$ \\
\hline
\end{tabular}




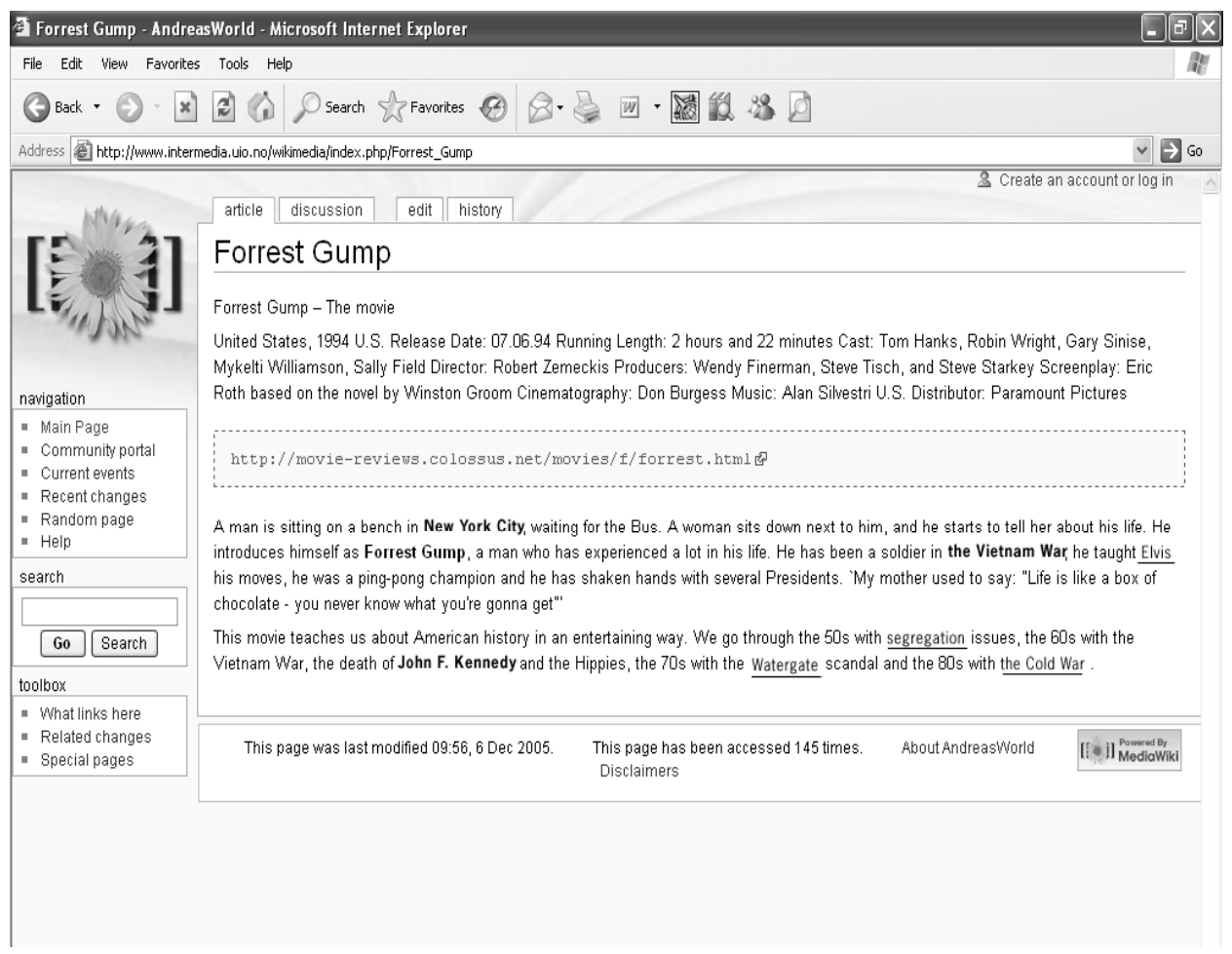

Fig. 2. Screenshot from emerging networked resource.

However, the broader, collective assignment requires that learners seek to link individual production to the dynamic and collective potential of the wiki. This involves trusting others to contribute productively and developing sensitivity towards the totality by relating one's own contribution to those of others, that is, we see the emergence of a collective ZPD.

Episode B takes place near the end of the project. After the initial local production, learners have increasingly started to explore the wiki's affordances. This did not come about as the result of an intervention, but happened gradually as learners oriented themselves towards the collective output. The wiki is now used as a repository for the texts produced by the class and as a network that links texts and text elements in a continuously growing hypertext. We see a sociogenetic process that results in a collective ZPD. In Table 2 we observe how Catherine and Marie decide on which words and terms need to be tagged with square brackets so that they appear in red and function as invitations to peer writing. They have completed their work on soaps and are now engaged in a presentation of the movie Forrest Gump.

Episode B emerges as different from episode A in several respects. Linguistically, oral production is basically deictic and pertains to the joint production of the hypertext (turns $4,6,9,18,19,21)$. Partly it indexes content to be linked; partly it indexes the procedures that add up to wiki construction. The videotape reveals deep concentration and extensive use of gestures and deictic moves. The available resources are not verbalized 
to the same extent as in episode A but function as joint references. The dual oral and written language production is still evident, but in this activity type the written mode has the priority. Figure 2 shows the screenshot from the wiki that developed from the interactions in episode B.

The teacher and researcher involved decided it would be interesting to see how learners experienced the collective ZPD and the transition from local and private production to distributed and collective production. An open-ended response form was distributed and responses analyzed. The form presented learners with a series of statements about wikis and asked them to say why they liked or disliked this, such as in the following example: "In a wiki anyone can add, edit, or delete a page. I like this because... / I do not like this because..." Typical responses were statements such as (all quotes as in the original response):

- I like this because we so easily can compare and share information on what we know and what we do not know about the American way of living

- I like this because it is a win/win situation. To help others and get help back is nice. Co-operating is very important in our daily lives and our future jobs!

- It doesn't matter if it is yours or others. This way it is possible for people to argue and discuss

- The subject will be shown from many persons view and not from one singular person [...] I feel like part of a team.

On the whole, the positive responses center upon the multi-voicedness and reciprocity of contributions as well as aggregated output. Together with the interaction data constituting the activity type seen in episode B we see how some processes of sociogenesis in language production are perceived by those involved.

In a language learning perspective it is interesting to note that learners were more reluctant to interfere with "somebody else's material", as they put it, than the linguistic representation. A conspicuous trait is that language proficient as well as less proficient learners expressed only positive responses, e.g.

- I know pretty mutch [sic] about different topics, but I am not always very good at expresing [sic] myself. I'm not very good at grammar and spelling either

- I like this because I don't write so well, but I have lots of knowledge I'd like to share.

As for the more negative statements, they are unanimous in their concern for abuse or inexpert editing. The following statements are typical:

- Someone can change what you have written, even when you know that what you have written is correct

- My texts got deleted.

Such concerns testify to the notions of ownership and individual accountability, although learners were aware that previous versions could be restored. These notions are characteristic of how school work traditionally has been linked to individual assessment and grades. Thus, we see the tensions between historical and institutional practices on 
the one hand, and on the other the emerging practices that in our introduction were linked to knowledge advancement and complex problem solving.

\subsection{Analysis}

By relating empirical samples to the theoretical argument two types of collaborative activity can be identified, which have been referred to as local collaborative and distributed collective language production. Although both can be characterized as collaborative, there is a marked difference between them as to the level and scope of the collaboration. The first type involves two or more learners working to develop topics in a self-contained and relatively autonomous mode. The focus is on a task or topic connected with the curriculum. It is in many ways typical of group work as it has developed within the historical and institutional "script" of schooling (Rasmussen, 2005; Wells, 1999). The second type involves branching out through responding to or creating links; the level of interdependence is heightened along with a more communal orientation. The focus shifts from local production to networked production, and with the use of links as invitations there is also the element of knowledge advancement - going beyond what learners produce in the first activity type. Thus, the second activity type can be considered "new" in the sense that the emergent collective ZPD is constituted partly by the type of task, partly by the affordances of the wiki, and partly by the activity types learners engage in. It does not carry the same institutional heritage and impact as the first activity type. At first, these types emerged as separate and consecutive activities but as the project progressed, learners gradually worked in mixed activity mode.

If we compare the activity types that materialize in the forms we see in episodes A and B we see a shift in epistemological position. In episode A the activities of Marie and Catherine do not extend beyond the dyad and into the collectively produced wiki. Their activities center around the topic while the networked representation has not started to form and they more autonomously draw on what they already knew about the topic. We see limited collective ownership (pair), but no wider communal orientation. In episode $\mathrm{B}$, however, the wiki emerged as a collective and dynamic object for knowledge construction. Although there is definitely collaboration in episode A, it is restricted to pair work. By linking their contributions to existing pages and linking to empty spaces for others to fill in, Marie and Catherine move from one kind of collaborative activity to another that involves the larger collective, and where production, revision and control are maintained by a distributed community. The log files as well as the videotapes show that this is very much the case for the class as a whole; we see a collective ZPD emerging as a result of sociogenesis.

That such collective production does not take place from the minute the wiki is introduced can be related to the historically solitary and private nature of writing, and not just in schools. Learners did not immediately embrace any notion of collective ownership but continued a practice where the institutionally cultivated individual ownership persisted. To understand this, as shown in the CALL research review section, it is not enough to focus on technological features: conceptualization of language learning and of the contexts in which language learning takes place emerges as a CALL research agenda. As it has been the intention of the current paper to respond to these needs, the final section will seek to briefly discuss some implications. 


\section{Discussion and conclusion}

This discussion is restricted to the collective ZPD, the sociogenetic aspects of language production, and the use of wikis. I return to the questions asked in the introduction what kind of wiki activities learners engage in, and what is the impact of wikis on the foreign language learning classroom?

The log files and the videotaped activities that document the wiki activity in this EFL class show transition from local collaboration to collective and networked production. Compared with much writing mediated by other types of technologies, wiki production suggests a shift in epistemological position for those involved. In this situation, learners are still unique and display individual agency. On the other hand, what they construct together with classmates cannot be reduced to the sum of discrete individual contributions only; the dynamically evolving wiki rests on the relations between participants as enacted in a collective ZPD. Response, trust, and interdependency are the driving forces. In a wiki, texts are not finite or "finished" but function as resources for expansion, reconfiguration, and new syntheses. How the technology mediates such intellectual interdependency serves to illustrate and support the conceptual argument of sociogenesis in (foreign) language production.

But the data from Hillside also reveals tensions; the impact is not unambiguous. Historically and institutionally, schooling has cultivated mostly an individual approach to writing (individual grades, exams), individual reproduction or problem-solving. Such an inheritance is not easily discarded or transformed. On the one hand we have an object for the activities that is characterized by individual ownership of technologies (pen, paper) as well as finalized outcomes (essays, translations etc). On the other hand we see the emergence of objects that cannot be recognized as the work of an individual and that are always in flux. Task construction and assessment that address collective practices are but two major challenges in the wake of such practices.

The activity types presented in the study show that a wiki affords collective production, networked structures, and shared spaces. Some researchers would even say that wikis require them (Garza \& Hern, 2006), although we have seen that it is the activity and not the technology per se that makes the difference. A wiki, at least the type we deal with here, does not make sense on an individual level. Consequently, wikis embody the essentially sociogenetic Bakhtinian (1979/2000, 1986/2004) notions of dialogicality, polyvocality and heteroglossia - that we come to knowledge through adding ours to the many and different voices that envelop us. Moreover, the wiki does not only document the product of these processes but also documents the process itself, even over long timescales, as each version of a page is saved, adding up to the full history of its development.

This study has aimed to examine emergent activity types in collective language production by juxtaposing theory, review and situations from the classroom. Findings indicate that an epistemological shift is involved and that this can be articulated in the form of diverse collaborative activity types. These findings can inform further research. Research topics that seem likely candidates are the potential value for participants' linguistic expansion (lexico-grammatical and semantic) when engaging in collective practices, the role of the language teacher in collective ZPDs, and the design of wiki features that support collective language production. 


\section{Acknowledgements}

The writing of this article is supported by the strategic research effort Competence and Media Convergence (CMC) at the University of Oslo, http://cmc.uio.no. Thanks to Ingvill Rasmussen and Sten Ludvigsen at InterMedia, University of Oslo for valuable suggestions. Also, thanks to the two anonymous reviewers for their constructive criticism.

\section{References}

Bakhtin, M. M. (1979/2000) The Dialogic Imagination. Four Essays by M.M. Bakhtin. Austin, TX.: University of Texas Press.

Bakhtin, M. M. (1986/2004) Speech Genres \& Other Late Essays (V. W. McGee, Trans. 9 ed.). Austin, TX: University of Texas Press.

Bax, S. (2003) CALL - past, present and future. System, 31: 13-28.

Brown, A. L. (1992) Design Experiments: Theoretical and Methodological Challenges in Creating Complex Interventions in Classroom Settings. The Journal of the Learning Sciences, 2(2): 141-178.

Brutt-Griffler, J. (2004) World English: A Study of its Development. Clevedon, Buffalo, Toronto: Multilingual Matters Ltd.

Daniels, H. (2001) Vygotsky and Pedagogy. New York and London: RoutledgeFalmer.

Design-Based Research Collective, T. (2003) Design-Based Research: An Emerging Paradigm for Educational Inquiry. Educational Researcher, 32(1): 5-8.

Dillenbourg, P. (1999) What do you mean by 'collaborative learning'? In: Dillenbourg, P. (ed.) Collaborative learning: Cognitive and computational approaches. Amsterdam: Pergamon, $1-16$.

Egbert, J. (2005) Conducting Research on CALL. In: Egbert, J. and Petrie, G. M. (eds.) CALL Research Perspectives. Mahwah, NJ and London: Lawrence, Erlbaum Associates, Inc., 3-8.

Egbert, J. and Petrie, G. M. (eds.) (2005) CALL Research Perspectives. Mahwah, NJ. and London: Lawrence Erlbaum Associates, Inc.

Engeström, Y. (1987) Learning by Expanding: An Activity - Theoretical Approach to Developmental Research. Helsinki: Orienta-konsultit.

Engeström, Y., Miettinen, R. and Punamäki, R. (eds.) (1999) Perspectives on Activity Theory. Cambridge: Cambridge University Press.

Ercikan, K. and Roth, W.-M. (2006) What Good Is Polarizing Research into Qualitative and Quantitative? Educational Researcher, 35(5): 14-23.

Garza, S. L. and Hern, T. (2006) Using Wikis as Collaborative Writing Tools: Something Wiki This Way Comes - Or Not! http://critical.tamucc.edu/wiki/WikiArticle/Home

Gibbons, P. (2006) Bridging Discourses in the ESL Classroom: Students, Teachers and Researchers. London and New York: Continuum.

Hakkarainen, K., Palonen, T., Paavola, S. and Lehtinen, E. (2004) Communities of Networked Expertise. Amsterdam: Elsevier/Earli.

Hall, J. K. and Verplaetse, L. S. (eds.) (2000) Second and Foreign Language learning Through Classroom Interaction. Mahwah, N.J.: Lawrence Erlbaum Associates.

Hall, J. K., Vitanova, G. and Marchenkova, L. (eds.) (2005) Dialogue with Bakhtin on Second and 
Foreign Language Learning: New Perspectives. Mahwah, NJ \& London: Lawrence Erlbaum Associates.

Hampel, R. (2006) Rethinking task design for the digital age: A framework for language teaching and learning in a synchronous online environment. ReCALL, 18(1): 105-121.

Hawkins, M. R. (ed.) (2004) Language Learning and Teacher Education: A Sociocultural Approach. Clevedon, Buffalo, Toronto: Multilingual Matters Ltd.

Heim, M. (1987) Electric Language. A Philosophical Study of Word Processing. Second Edition with a Foreword by David Gelernter (2nd ed.) New Haven \& London: Yale University Press.

Huh, K. and Hu, W. (2005) Criteria for Effective Call Research. In: Egbert, J. and Petrie, G. M. (eds.) CALL Research Perspectives. Mahwah, NJ and London: Lawrence Erlbaum Associates, Inc., 9-21.

Johnson, K. E. (2006) The Sociocultural Turn and Its Challenges for Second Language Teacher Education. TESOL Quarterly, 40(1): 235-257.

Jordan, B. and Henderson, A. (1995) Interaction Analysis: Foundation and Practice. Journal of the Learning Sciences, 4(1): 39-103.

Kaptelinin, V. and Nardi, B. A. (2006) Acting with Technology: Activity Theory and Interaction Design. Cambridge, MA and London: MIT Press.

Kern, R. (2006) Perspectives on Technology in Learning and Teaching Languages. TESOL Quarterly, 40(1): 183-210.

Kern, R., Ware, P. and Warschauer, M. (2004) Crossing Frontiers: New Directions in Online Pedagogy and Research. Annual Review of Applied Linguistics(24): 243-260.

Kostogriz, A. (2005) Dialogical Imagination of (Inter)cultural Space: Rethinking the Semiotic Ecology of Second Language and Literacy Learning. In: Hall, J. K., Vitanova, G. and Marchenkova, L. (eds.) Dialogue with Bakhtin on Second and Foreign Language Learning. Mahwah, N.J. \& London: Lawrence Erlbaum Associates Publishers, 189-210.

Kvale, S. (1996) InterViews. Thousand Oaks, CA: SAGE.

Lantolf, J. P. (2000a) Second language learning as a mediated process. Language Learning, 33(2): 79-96.

Lantolf, J. P. (ed.) (2000b) Sociocultural Theory and Second Language Learning. Oxford: Oxford University Press.

Lantolf, J. P. and Thorne, S. L. (2006) Sociocultural Theory and the Genesis of Second Language Development. Oxford: Oxford University Press.

Leuf, B. and Cunningham, W. (2001) The Wiki Way: Quick Collaboration on the Web. Boston, MA: Addison-Wesley Longman Publishing Co.

Lindkvist, L. (2005) Knowledge Communities and Knowledge Collectivities: A Typology of Knowledge Work in Groups. Journal of Management Studies, 42(6): 1189-1210.

Linell, P. (1998) Approaching Dialogue: talk, interaction and contexts in dialogical perspectives. Philadelphia/Amsterdam: John Benjamins.

Ludvigsen, S. (in press) What counts as knowledge: Learning to use categories in computer environments. In: Säljö, R. (ed.) ICT and Transformation of Learning Practices. Oxford: Pergamon.

Lund, A. (2004) The Teacher as Interface. Teachers of EFL in ICT-Rich Environments: Beliefs, Practices, Appropriation. Doctoral dissertation, University of Oslo.

Lund, A. (2005) Collective Epistemologies in an Upper Secondary School. A Preliminary Analysis. Paper presented at the EARLI conference, Nicosia, Cy. 
Lund, A. (2006) The Multiple Contexts of Online Language Teaching. Language Teaching Research, 10(2): 181-204.

Lund, A. and Smørdal, O. (2006) Is There a Space for the Teacher in a Wiki? In: Proceedings of the 2006 International Symposium on Wikis (WikiSym '06). Odense, Denmark: ACM Press, 37-46.

Mercer, N. (2000) Words and Minds: how we use language to think together. London and New York: Routledge.

Ong, W. (1982/1988) Orality and Literacy. The Technologizing of the Word. New York: Methuen.

Pew Internet and American Life Project (2002) The digital disconnect: The widening gap between Internet-savvy students and their schools. http://www.pewinternet.org/pdfs/PIP_Schools_ Internet_Report.pdf

Rasmussen, I. (2005) Project work and ICT. A study of learning as trajectories of participation. Doctoral Dissertation, University of Oslo, Oslo.

Riehle, D. (2006) How and Why Wikipedia Works: An Interview with Angela Beesley, Elisabeth Bauer, and Kizu Naoko. In: Proceedings of the 2006 International Symposium on Wikis (WikiSym '06). Odense: ACM Press, 3-8.

Roberts, C. (2001) Language Acquisition or Language Socialisation in and through Discourse? Towards a Redefinition of the Domain of SLA. In: Candlin, C. and Mercer, N. (eds.) English Language Teaching in its Social Context. London and New York: Routledge, 108-121.

Roth, W.-M. (2005) Tracking Situated, Distributed, and Embodied Communication in Real Time. In: Vanshevsky, M. A. (ed.) Focus on Cognitive Psychology Research: Nova Science Publishers, Inc., 237-261.

Stahl, G. (2006) Group Cognition: Computer Support for Building Collaborative Knowledge: MIT Press.

Säljö, R. (2000) Lärandet i praktiken. Ett sociokulturellt perspektiv. [Learning in Practice: A sociocultural perspective]. Stockholm: Prisma.

Thorne, S. L. (2003) Artifacts and Cultures-of-Use in Intercultural Communication. Language Learning and Technology, 7(2): 33-67.

Thorne, S. L. and Payne, J. S. (2005) Evolutionary Trajectories, Internet-mediated Expression, and language Education. CALICO Journal, 22(3): 371-397.

Tomasello, M. (2003) Constructing a language: a usage-based theory of language acquisition. Cambridge, MA and London: Harvard University Press.

Valsiner, J. and van der Veer, R. (2000) The Social Mind. Construction of the Idea. Cambridge: Cambridge University Press.

Vollmer, G. (2002) Sociocultural Perspectives on Second Language Writing. ERIC Clearinghouse on Languages and Linguistics, 25(2): 1-3.

Vygotsky, L. S. (1978) Mind in Society: the development of higher psychological processes. Cambridge, Mass.: Harvard University Press.

Vygotsky, L. S. (1986) Thought and Language (A. Kozulin, Trans.). Cambridge, Ma: MIT Press.

Warschauer, M. (1999) Electronic Literacies. Language, Culture and Power in Online Education. Mahwah, NJ: Lawrence Erlbaum Associates.

Warschauer, M. and Kern, R. (eds.) (2000) Network-based Language Teaching: Concepts and Practice. Cambridge: Cambridge University Press.

Watson-Gegeo, K. A. (2004) Mind, Language and Epistemology: Toward a Language 
Socialization Paradigm for SLA. The Modern Language Journal, 88(iii): 331-350.

Wells, G. (1999) Dialogic Inquiry. Towards a Sociocultural Practice and Theory of Education. Cambridge: Cambridge University Press.

Wertsch, J. V. (1998) Mind As Action. Oxford: Oxford University Press.

Zhao, Y., Pugh, K., Sheldon, S. and Byers, J. L. (2002) Conditions for Classroom Technology Innovations. Teachers College Record, 104(3): 482-515.

Zuengler, J. and Miller, E. R. (2006) Cognitive and Sociocultural Perspectives: Two Parallel SLA Worlds? TESOL Quarterly, 40(1): 35-58. 